\title{
Drag and inertia coefficients for horizontally submerged rectangular cylinders in waves and currents
}

\author{
V Venugopal $^{1}$, K S Varyani ${ }^{2 *}$, and P C Westlake ${ }^{3}$ \\ ${ }^{1}$ Institute for Energy Systems, School of Engineering and Electronics, University of Edinburgh, Edinburgh, UK \\ ${ }^{2}$ Department of Naval Architecture and Marine Engineering, Universities of Glasgow and Strathclyde, Glasgow, UK \\ ${ }^{3}$ Fyvie, Aberdeenshire, UK
}

The manuscript was received on 24 June 2008 and was accepted after revision for publication on 27 October 2008.

DOI: $10.1243 / 14750902 J E M E 124$

\begin{abstract}
The results of an experimental investigation carried out to measure combined wave and current loads on horizontally submerged square and rectangular cylinders are reported in this paper. The wave and current induced forces on a section of the cylinders with breadthdepth (aspect) ratios equal to $1,0.5$, and 0.75 are measured in a wave tank. The maximum value of Keulegan-Carpenter $(K C)$ number obtained in waves alone is about 5 and Reynolds $(R e)$ number ranged from $6.397 \times 10^{3}$ to $1.18 \times 10^{5}$. The drag $\left(C_{\mathrm{D}}\right)$ and inertia $\left(C_{\mathrm{M}}\right)$ coefficients for each cylinder are evaluated using measured sectional wave forces and particle kinematics calculated from linear wave theory. The values of $C_{\mathrm{D}}$ and $C_{\mathrm{M}}$ obtained for waves alone have already been reported (Venugopal, V., Varyani, K. S., and Barltrop, N. D. P. Wave force coefficients for horizontally submerged rectangular cylinders. Ocean Engineering, 2006, 33, 1112, 1669-1704) and the coefficients derived in combined waves and currents are presented here. The results indicate that both drag and inertia coefficients are strongly affected by the presence of the current and show different trends for different cylinders. The values of the vertical component inertia coefficients $\left(C_{\mathrm{MY}}\right)$ in waves and currents are generally smaller than the inertia coefficients obtained in waves alone, irrespective of the current's magnitude and direction. The results also illustrate the effect of a cylinder's aspect ratio on force coefficients. This study will be useful in the design of offshore structures whose columns and caissons are rectangular sections.
\end{abstract}

Keywords: Morison equation, rectangular cylinder, wave and current force, drag and inertia coefficients, low Keulegan-Carpenter number

\section{INTRODUCTION}

Currents commonly occur in the ocean and offshore platforms operate in areas where waves propagate on currents. The interaction of waves and currents and the resulting effect on the response of structures must be considered in the design. The existence of currents will change the wave parameters and wave kinematics. Wave and current loading on offshore structures is of a highly non-linear nature owing to the non-linear drag force and free surface effects. These non-linearities may introduce non-linear

*Corresponding author: Department of Naval Architecture and Marine Engine, Universities of Glasgow and Strathclyde, Glasgow G4 OLZ,UK.email: k.s.varyani@na-me.ac.uk structural response even if the structure acts as a linear system. Furthermore, non-linear behaviour also implies that the hydrodynamic drag damping, caused by the relative velocity between the structure and the surrounding fluid, is very important and there are significant uncertainties related to the calculation of environmental loads. In order to achieve a better understanding of the fluid mechanics associated with these flows, laboratory and computational studies are essential.

Semi-submersible drilling rigs and tension leg platforms with members of rectangular cross-section are emerging. In order to determine the optimum geometry of these members for a reduction in wave forces and good performance in waves, accurate predictions of the hydrodynamic forces acting on the 
members are required. Research into hydrodynamic wave-current loading on offshore structures has concentrated mostly on members of circular crosssection and relatively limited work has been carried out on wave-current loading on other cross-sections such as a rectangular section. When a structure is subjected to combined wave and current action, the interaction becomes a complex phenomenon, which makes the prediction of fluid loading on the structure very difficult.

In an experiment with a U-tube water tunnel, Bearman et al. [1] measured wave forces on flat plates, circular, square, and 'diamond' cross-sections cylinders and calculated $C_{\mathrm{D}}$ and $C_{\mathrm{M}}$. They found that at low $K C$ numbers $(\leqslant 10)$, the values of $C_{\mathrm{D}}$ for flat, square, and diamond sections were generally found to be decreasing with increasing $K C$ compared with a circular cylinder. Highest values of inertia coefficients were obtained for square cylinders in comparison with other sections. Wave force measurements were also conducted by Ikeda et al. [2] on circular, flat plate, square, and diamond sections, which were horizontally submerged in regular waves at low $K C$ numbers. Ikeda et al. found that for a flat plate the drag and inertia coefficients measured in waves were lower than those measured in oscillatory flow by Tanaka et al. [3]. In another study, Ikeda et al. [4] also measured the viscous forces acting on a horizontally submerged lower hull of a semi-submersible (a rectangular cylinder with rounded corner with aspect ratio $=0.533$ ) with its axis parallel to the wave crest and found that at low $K C$ numbers, the inertia coefficients decrease rapidly with increasing $K C$ number. Ikeda et al. reported that this decrease in inertia force is attributable to a Magnus effect (a lift force effect produced by a circulating flow). This reduction in inertia force was also noticed by Chaplin $[5,6]$ for a circular cylinder and this was caused by a circulating flow (a steady vortex motion) around the cylinder. In another study, Chaplin and Retzler [7] carried out experimental and numerical studies on horizontal cylinders of circular and pontoon sections and found a reduction in added mass coefficients with $K C$ number. They concluded that while the reduction in added mass coefficient for a circular cylinder is proportional to the square of the $K C$ number, for the pontoon section this reduction is simply proportional to $K C$ numbers. Arai $[\mathbf{8}, 9]$ measured wave forces on rectangular cylinders and found that the inertia coefficients for all the cylinders decreased at low $K C$. Arai noticed that the circulation of the flow for all the cylinders was almost the same and was proportional to the square of the $K C$ number.
Venugopal et al. [10] measured sectional wave forces on one square and two rectangular cylinders (note: the same cylinders were used for measuring combined wave and current forces in the present paper) in regular and irregular waves and derived drag and inertia coefficients at low $K C$ numbers. Their analysis showed that at very low $K C$ numbers the inertia coefficients for all cylinders approached the potential flow values for both horizontal and vertical forces. The drag coefficients at low $K C$ numbers exhibited large values and these coefficients decreased sharply with increase in $K C$ number for all cylinders. The high drag coefficients at low $K C$ numbers are associated with the flow separation and the first appearances of vortices, which take place for sharp-edged rectangular cylinders at very low $K C$ numbers. At lower values of $K C$ number, the inertia coefficients approached their potential flow values. Inertia coefficients decreased with the increase in $K C$ number, owing to the presence of a circulating flow around the cylinders, up to the range of $K C$ numbers tested. For a square cylinder, the reduction in inertia coefficient reached about 50 per cent at a value of $K C$ number around 3.0-4.0 and a further increase in $K C$ resulted in an increase in the inertia coefficients.

Other notable experimental contributions for rectangular cylinders may be found in references [11] to [13].

With reference to wave and current loading on rectangular cylinders, not many studies have been conducted in the past. Chaplin and Retzler [14] described experimental and numerical predictions of the flow and forces around a horizontal circular cylinder and a pontoon section in waves with and without currents for $K C$ numbers below 2. They reported a similar behaviour for both these sections. In an extreme case, in the presence of a current of 1.8 times the speed of the undisturbed oscillatory flow, the inertia coefficient for the vertical oscillatory loading was reduced from its potential flow value by 50 per cent.

The above literature review indicates that a large amount of work has already been carried out on rectangular cylinders; however, the present study has been undertaken because the force coefficients reported in the past (e.g. references [1] , [3], and [15]) correspond to the experiments performed either in a U-tube set-up or a cylinder oscillating in still water, where the cylinder was either held fixed in an harmonically oscillating fluid or the cylinder oscillated harmonically in still water with a given frequency and amplitude. In both the cases the flow is onedimensional; whereas, when tests are conducted in a 
Table 1 Cylinder model details

\begin{tabular}{lll}
\hline Cylinder type & Sectional dimensions $(\mathrm{mm})$ & Sectional ratio \\
\hline Square & $150 \times 150$ & 1.0 \\
Rectangle & $200 \times 400$ & 0.5 \\
Rectangle & $300 \times 400$ & 0.75 \\
\hline
\end{tabular}

wave flume or basin, the flow is two-dimensional such that the free stream velocity field varies in both horizontal and vertical directions, and the generated waves are not necessarily sinusoidal. Furthermore, the development of the boundary layer and separation points are different between planar motion and wave motion and therefore the pressure distribution around the structure will be different in both the methods; this would yield differences in measured forces (see, for example, Chakrabarti [16], pp. 118-119).

Moreover, most of the experimental investigations in the laboratories, including those described above, correspond to small-scale experiments, usually carried out at a Reynolds number too low to be representative of real conditions. Information thus obtained cannot usually be confidently extrapolated to real sea conditions. Among the very few results available for sharp-edged rectangular cylinders, those reported by Arai [8] correspond to a frequency parameter ( $\beta$, defined by $R e / K C$ ) from 750 to 6470 . Although sharp-edged square cylinders are known to be less sensitive to Reynolds number effects in steady flow, it would be interesting to examine the effects in wavy flow on what would be the change in the force coefficients if the cylinders were tested at higher $\beta$ values. Hence, the primary objective of this present study is to evaluate the hydrodynamic force coefficients for large-scale rectangular cylinders in waves and currents.

\section{EXPERIMENTAL DESCRIPTION}

\subsection{Cylinder models}

The description of the square and rectangular cylinders used for the experimental investigation may also be found in references [10] and [17]. The cylinders were constructed using $7 \mathrm{~mm}$ thick polyvinyl chloride (PVC) plates with internal bulkheads spaced equally along the length of the cylinder. Three cylinders were used for the tests and the details are provided in Table 1 . The cylinders were made of three hollow sections connected by an inner rectangular beam at the centre. A $100 \mathrm{~mm}$ long 'test section' instrumented with load cells was situated at the mid-length of the cylinders. The total length of each cylinder was $2 \mathrm{~m}$ after the three sections were joined together and their surface was smoothly painted. The test section was separated from the adjacent dummy sections by a narrow slit of $2-3 \mathrm{~mm}$ to avoid the interference from the dummy sections and this gap was then covered by a flexible thin rubber sheet to prevent water entering the load section. To study the effect of orientation of the cylinder with respect to the incoming waves, a term was defined as 'aspect ratio', which was taken as the ratio between the dimension of the cylinder normal to the wave direction and the dimension of the cylinder parallel to the wave direction. The cylinders' sectional dimensions and the corresponding section ratios are presented in Table 1. In order to conduct experiments at high Reynolds numbers and at low Keulegan-Carpenter numbers, large-sized cylinders were chosen.

\subsection{Description of the towing tank}

Wave-current force measurements were carried out in the towing tank of the Hydrodynamic Laboratory of the Department of Naval Architecture and Ocean Engineering at the University of Glasgow. The dimensions of the tank are $4.6 \mathrm{~m}$ wide, $2.7 \mathrm{~m}$ deep, and $77 \mathrm{~m}$ long with a working water depth of $2.4 \mathrm{~m}$. The experiments for the present study were conducted at a water depth of $2.2 \mathrm{~m}$. The tank is equipped with an electro-hydraulic paddle/flap type wave maker fitted across the width of the tank at one end. The wave maker can generate regular and random waves in the frequency range of $0.4-1.4 \mathrm{~Hz}$. At the other end of the tank, an inclined mesh beach of $6 \mathrm{~m}$ length is fitted to absorb the energy of the oncoming waves and the beach effectively dissipated most of the wave energy. The tank is also equipped with an electronically controlled towing carriage with an observation platform, whose dimensions are approximately of $5 \mathrm{~m} \times 6 \mathrm{~m}$ in plan, and running on rails with a maximum carriage speed of $6.4 \mathrm{~m} / \mathrm{s}$. The carriage is driven by four on-board servo-controlled electric motors.

The cylinder was rigidly fixed on to the carriage and positioned at the centre of the tank width using a specially designed frame that avoids any vibrations and movements during the wave impact. The centre of the test section was located at $0.47 \mathrm{~m}$ from the still water level (SWL). The carriage with cylinder was positioned $25 \mathrm{~m}$ away from the wave maker when the measurements were made for waves alone. In the present experiments, the end effects on the force measurements were assumed to be negligible as the force measurements were made only on the mid 
$100 \mathrm{~mm}$ instrumented section of a two-metre cylinder, which is located between two dummy sections. It is to be noted that the cylinders in fact had end plates of rectangular shape at their ends; however, they were primarily used as a joining plate to the supporting frames rather than acting as end plates. Even though they were not designed to the proper end plates' design requirements, still they can be considered as end plates. The force coefficients from reference $[\mathbf{1 0}]$ for horizontal rectangular cylinders compared very well with results of references [2], [8], [9], and [15] and this reveals that these plates might have acted as a proper end plate to some extent to give a two-dimensional flow around the cylinder. However, it cannot be denied that the experiments are completely free from end effects and the results may have been affected by the three-dimensional flow around the cylinder end, although not to a great extent. If the force measurements were made on the total length of the cylinder, then it would not be so easy to make the above statement, as the end effects would certainly have influences on the coefficients. Furthermore, the following literature is considered here to show that the present experiments could be free from end effects; Nakamura et al. [18] experimentally investigated the three-dimensional effects of hydrodynamic forces acting on finite length vertical circular cylinders each of $32 \mathrm{~mm}$ diameter, in an oscillating flow. Four cylinders of different length to diameter ratios $(l / D=1,3,10,20)$ were used without end plates and one cylinder with $l / D=3$ was fitted with end plates of diameter $160 \mathrm{~mm}$ (equal to five times the cylinder's diameter). The cylinder with $l / D=20$ was called a quasi-twodimensional cylinder. The hydrodynamic coefficients were computed from simple harmonic forced surging tests on the cylinders for $K C=4-40$. Their analyses showed that the $C_{\mathrm{D}}$ for a quasi-two-dimensional cylinder is slightly smaller than $C_{\mathrm{D}}$ for the cylinder with end plates; and for finite length cylinders $C_{\mathrm{D}}$ decreased with decrease of $l / D$. The inertia coefficients decreased with increasing $l / D$ and the lift coefficients increased with increase in $l / D$. However, the important point to be noted here is that Nakamura et al. $[\mathbf{1 8}]$ claimed that at the region of $K C \leqslant 8$, there were no differences in the inertia coefficients between the quasi-two-dimensional cylinder and the finite length cylinders. A similar trend was also seen for lift coefficients, where the coefficients for all the cylinders appear to be showing similar values at this range of $K C$ numbers. However, $C_{\mathrm{D}}$ showed a slightly higher values for cylinders with $l / D=20$ and also for a quasi-two-dimensional cylinder. From another experimental study on circular cylinders Hoshino et al. [19] showed that, at $K C$ less than about 6 , varying $l / D$ ratio did not show any significant change in the inertia and lift coefficients and the values were virtually same as those obtained for a cylinder with $l / D=\infty$. The above results confirm that the length to diameter ratio of a cylinder will influence the hydrodynamic coefficients only for higher $K C$ values. In the present study the values of $K C$ obtained are less than 6 and therefore it may be reasonable to accept that the end effects might not have influenced the force coefficients at low values of $K C$.

The deflections for the cylinder models at the location of the test section, both in vertical and horizontal fixing modes, are found to be very small, in the order of a few millimetres. Further details may be found in reference [10].

\subsection{Wave and force measurements}

The waves were generated using the software, 'WAVE', developed at the Hydrodynamics Laboratory, Glasgow University. It is a simple program that reads in a time series file of voltage values and sends that value via a data acquisition (D/A) card in the computer to the wave maker control hardware. For regular wave tests, the wave heights selected ranged from 0.05 to $0.38 \mathrm{~m}$ and the wave periods ranged from 0.8 to $2.325 \mathrm{~s}$. For each aspect ratio of the cylinder, experiments were carried out for about 50 waves with different combinations of wave heights and wave periods. Some of the long period waves were disturbed by the reflected waves after a time period of about $40-50 \mathrm{~s}$, and those data with reflection were excluded from the analysis. A resistance type wave probe was placed in transverse line with the axis of the cylinder to measure the wave profile and phase angles. The wave profile and forces were recorded for $60 \mathrm{~s}$ with a sampling interval of $0.025 \mathrm{~s}$. The maximum value of $K C$ number obtained in waves alone (i.e. without including the current effect) is about 5.0 and the $R e$ number varied from $6.397 \times 10^{3}$ to $1.18 \times 10^{5}$.

To study the wave-current-cylinder interaction, the cylinders were towed in regular waves for following sea (positive current) and head sea (negative current) to produce co-existing wavecurrent effect. The cylinders were towed with speeds of $0.1 \mathrm{~m} / \mathrm{s}, 0.2 \mathrm{~m} / \mathrm{s}$, and $0.3 \mathrm{~m} / \mathrm{s}$ in both directions. The data were collected using a data acquisition software known as LabVIEW 4.1, by National Instruments Corporation. 
The test section was instrumented with four waterproof strain gauge type load cells; one load cell was fixed on each side of the cylinder to measure the forces on the test section. The load cells were NOVATECH model of type F255, manufactured by Novatech Measurements Ltd, UK, made of stainless steel body with a diameter of $30 \mathrm{~mm}$ and a height of $16 \mathrm{~mm}$, and submersible in water. The load cells had two welded stainless steel diaphragms on the top and bottom sides of the active element to protect the load cell. Four strain gauges were in each load cell, making a full bridge connection. Each load cell was capable of measuring tension and compression loads up to $25 \mathrm{kgf}$. The load cells had a threaded stud on the base, which was threaded into the cylinder's inner beam flange at the height of the test section, and an active threaded stud, which was threaded to one plate of the test section covering it and formed one face of the test section. In a similar way, the other faces of the test section were assembled. The average of the forces measured by the two load cells, fixed on opposite sides of the inner rectangular beam, was taken as the force acting from the corresponding direction. The load cells were connected to an amplifier, one load cell per channel. The cylinders were submerged in water for about 48 hours to make sure that they were watertight.

\section{THEORY AND DATA ANALYSIS}

In the calculation of wave forces on cylinders the semi-empirical force model developed by Morison $e t$ al. [20] has been most widely used since its first introduction. This approach depends upon knowledge of water particle kinematics and empirically determined force coefficients, $C_{\mathrm{D}}$ and $C_{\mathrm{M}}$. In the present laboratory study it was not possible to measure the water particle velocity beside the structure as no instrument was available. Hence the wave particle kinematics computed using linear wave theory was used in Morison's equation to calculate the wave forces. The procedure of using linear wave theory to compute particle kinematics and its accuracy have been discussed in reference [21] for force measurements on vertical rectangular cylinders.

In waves, the incident flow is usually orbital with the type of orbit depending on the ratio of the wavelength to the water depth. A vertical cylinder will therefore be subjected to different flow conditions including a span-wise velocity component if it is long enough. A horizontal cylinder on the other hand may have the same incident flow along its span but the wake interaction would be different to that of a vertical cylinder; unless the orbit is flat. For the vertical cylinder, regardless of the orbit, the wake will be swept back against the cylinder; but for the horizontal cylinder the wake will in general follow the orbital path. Depending on the orbit, the vortices shed from the previous half cycle on a horizontal cylinder may be swept far enough away from the cylinder, so that when the flow reverses they may not significantly affect the forces on the cylinder. Also, for a horizontal cylinder fully submerged in regular, deep water waves with its axis parallel to the wave crests, the plane of the water particles' circular orbits is normal to the axis of the cylinder with no axial component of velocity, and also no variation in phase along the length of the cylinder. The forces associated with vortex shedding are co-planar with the orbits and hence there is no force transverse to the plane of the orbits. The velocity vector, constant in magnitude, has vertical and horizontal components both normal to the axis of the cylinder and with associated forces having vertical and horizontal periodic components. A very detailed description of flow around cylinders may be found in reference [22].

Hence, for a horizontal cylinder in waves, the vertical component of the water particle velocity is also significant and to account for this a modified form of the Morison equation needs to be used in the force calculation. Chaplin [23] discussed the effects of the free surface and bed boundaries, effects of circulation, and the form of Morison's equation to be used for a horizontal cylinder in waves. Chaplin [23] reported that a good agreement between measured and simulated forces could be obtained by assigning separate force coefficients for the vertical and horizontal directions. The modified form of the Morison's equation used for the present work to calculate the forces per unit length of the horizontal rectangular cylinder is expressed as

$$
\begin{aligned}
& F_{X}=\frac{1}{2} \rho C_{\mathrm{D} X} D u \sqrt{\left(u^{2}+w^{2}\right)}+\rho C_{\mathrm{M} X} A \dot{u} \\
& F_{Y}=\frac{1}{2} \rho C_{\mathrm{D} Y} B w \sqrt{\left(u^{2}+w^{2}\right)}+\rho C_{\mathrm{M} Y} A \dot{w}
\end{aligned}
$$

where $F_{X}$ is the wave force in the horizontal direction; $F_{Y}$ is the wave force in the vertical direction; $C_{\mathrm{DX}}$ is the drag coefficient in the horizontal direction; $C_{\mathrm{D} Y}$ is the drag coefficient in the vertical direction; $C_{\mathrm{MX}}$ is the inertia coefficient in the horizontal direction; $C_{\mathrm{M} Y}$ is the inertia coefficient in the vertical direction; $D$ is the cylinder's section depth in the vertical 
direction; $B$ is the cylinder's section width in the horizontal direction; $A$ is the cross-sectional area of the cylinder; $u$ is the horizontal particle velocity; $\dot{u}$ is the horizontal particle acceleration; $w$ is the vertical particle velocity; $\dot{w}$ is the vertical particle acceleration; and $\rho$ is the density.

In addition to the drag and inertia forces, a lift force is also associated with the loading on a horizontal cylinder. This lift force is perpendicular to the velocity vector and rotates around the axis of the cylinder because of the orbital motion of the water particles. However, the magnitude, direction, and period of the lift force are unknown, they cannot be added to the Morison's equation and the effect of the vortex shedding will therefore be shown up as noise in the measurements of the drag and inertia components [24].

Sarpkaya and Storm [25] discussed how the coexisting flow fields in a laboratory can be produced by: (a) translating a cylinder in a flume, (b) oscillating a cylinder in a uniform stream, (c) moving a cylinder with constant velocity while oscillating it in the desired direction, (d) subjecting a fixed cylinder to an oscillating flow with a mean velocity, or (e) translating a cylinder in an oscillating flow; they suggested that the method (e) will be more suitable in isolating the effect of current on fluid loading. Teng and Nath [24] mentioned that towing a cylinder with uniform speed in a wave field takes into account the orbital motion of the water particles and it simulates the linear superposition principle for considering waves and current together. This method is found to be easier and realistic in situations where the simultaneous generation of waves and current is not possible and hence this method was followed in the present study.

For horizontal cylinders, the Morison's equation can be modified to account for the coexisting case of waves and currents by replacing ' $u$ ' by ' $u \pm U_{\mathrm{C}}$ ', where $u$ is the horizontal water particle velocity and $U_{\mathrm{C}}$ is the current speed. The horizontal and vertical forces are calculated from the following expressions

$$
\begin{aligned}
F_{X}= & \frac{1}{2} \rho C_{\mathrm{D} X} D\left(u \pm U_{\mathrm{C}}\right) \sqrt{\left[\left(u \pm U_{\mathrm{C}}\right)^{2}+w^{2}\right]} \\
& +\rho C_{\mathrm{M} X} A \dot{u} \\
F_{Y}= & \frac{1}{2} \rho C_{\mathrm{D} Y} B w \sqrt{\left[\left(u \pm U_{\mathrm{C}}\right)^{2}+w^{2}\right]} \\
& +\rho C_{\mathrm{M} Y} A \dot{w}
\end{aligned}
$$

One of the most straightforward methods for estimating the force coefficients, used in both time domain and frequency domain analysis, is the leastsquares method. Using numerical simulation of wave forces, Isaacson et al. [26] reported that the method of least squares is reliable and accurate. The method of least squares approach has the most general application as it can also be applied in cases where the water particle kinematics are not sinusoidal as for irregular waves or non-linear waves. This method consists of the minimization of the error between the measured and calculated force-time histories and results in constant values of drag and inertia coefficients. As the least-squares method was found to provide reliable force coefficients when the wave kinematics are directly measured or computed using a suitable wave theory, it was followed here for the analysis of wave force data. This method was applied to every individual wave cycle defined by zero down crossing method to compute $C_{\mathrm{D}}$ and $C_{\mathrm{M}}$ values. The average values of $C_{\mathrm{D}}$ and $C_{\mathrm{M}}$ were then presented against $K C$ number. The $K C$ number and Re numbers are defined below, and were again obtained for each wave cycle and then averaged over the number of waves

$$
\begin{aligned}
& K C=\frac{U_{\mathrm{m}} T}{B} \\
& R e=\frac{U_{\mathrm{m}} B}{v}
\end{aligned}
$$

where $U_{\mathrm{m}}$ is the maximum horizontal particle velocity at the elevation of the centre of the test section, $B$ is the width or the dimension of the cylinder parallel to the wave direction, $v$ is the kinematic viscosity, and $T$ is the wave period. The $K C$ number is a measure of the water particle orbital amplitude with respect to the cylinder diameter and has been defined in terms of the amplitude of the water particle velocity. This gives the relationship of the circumference of the wave particle path to the structural diameter. The Reynolds number arises from the ratio of inertia force to viscous force.

Sarpkaya and Storm [25] have listed the various possible Keulegan-Carpenter and Reynolds numbers to relate the data in a better way and also to reduce the number of governing parameters for the coexisting wave and current conditions. The following expressions are used in the present study

Kuelegan-Carpenter number

$$
K C\left[1+\left|\left(\frac{U_{\mathrm{C}}}{U_{\mathrm{m}}}\right)\right|\right]
$$


Reynolds number

$$
R e\left[1+\left|\left(\frac{U_{\mathrm{C}}}{U_{\mathrm{m}}}\right)\right|\right]
$$

In the above expressions, $K C$ and $R e$ are calculated by equations (5) and (6) respectively. Equations (7) and (8) will be used in the following sections to express Kuelegan-Carpenter numbers and Reynolds numbers respectively for all the coexisting wave and current cases.

\section{APPLICATION TO SUBSEA INSTALLATION ANALYSIS}

Simple methods for estimating the likely maximum downward and upward forces during the splash zone transit of a subsea structure have been well established for some time, for example, Det Norsk Veritas [27]. For secure operations the maximum downwards force should be less than the safe working load of the crane at its working radius and the number of falls reeved while the maximum upward hydrodynamic force must be less than the net static weight of the structure to ensure slack lines and snap loads do not occur. As both the fluid and vessel motions are a function of sea state, a significant wave height is sought for installation operations in order that both these conditions are satisfied over a sensible range of wave zero crossing periods.

In most circumstances once the structure has passed through the free surface and the possibility of an upward slamming force is diminished the most critical condition occurs when the structure is just submerged. In this position the resultant vertical force is composed predominately of inertia and damping components, similar to that stated in equation (1). The inertia force of an oscillating body in waves comprises (a) the product of the relative vertical acceleration between the structure and the undisturbed water particles and the added mass plus (b) the product of water particles' acceleration and mass of the structure. The damping force is proportional to the product of the damping coefficient and the square of the relative vertical velocity between the structure and the water particles.

Although the procedure is routine the applicability of the calculation and hence the derivation of the maximum permissible installation significant wave height hinges upon the correct selection of the heave added mass and damping coefficient. In general, as previously outlined, these are a function of the
Reynolds and Keulegan-Carpenter numbers as well as the geometry of the structure.

In the past it has been commonplace when completing an installation analysis to ignore these dependences and inconsistently assume the heave added mass and damping coefficients to be constants. The value of the heave added mass is taken in the high-frequency limit $(K C \rightarrow 0)$, however, in reality, the added mass of an object may differ considerably from this value. Furthermore, owing to the absence of an appropriate oscillatory flow damping coefficient, usually assumed to comprise a linear and quadratic component, it has been customary to utilize a steady flow drag coefficient, that is, the low-frequency limit of the damping coefficient $(K C \rightarrow \infty)$. This assumption is non-conservative as the ratio of damping to drag coefficient may be large, especially at low $K C$ number. The augmentation of drag is caused by the object oscillating in its own wake rather than experiencing a uniform inflow. At large $K C$ the effects of the wake diminish and the damping coefficient will tend to the drag coefficient. Also, during lowering, the wake may be left above the object and the damping coefficient may reduce to a drag coefficient type value, the degree of reduction being a function of the ratio of the object's oscillatory and lowering velocities.

The uncertainties associated with the heave added mass and the total damping level have cast doubts on the value of installation analyses. The experimental data presented in the current paper aim to address these deficiencies.

\section{RESULTS AND DISCUSSIONS}

\subsection{Validation of steady flow force measurements}

In order to validate force measurements in currents, steady towing tests were carried out on all the cylinders. A cylinder immersed either vertically or horizontally in steady flow would experience a similar flow pattern and hence would be subjected to an identical drag force. The drag coefficient in steady towing can be calculated as $C_{\mathrm{D}}=F /\left(0.5 \rho U^{2} A\right)$, where $F$ is the mean horizontal force, $U$ the carriage speed, and $A$ is the cylinder projected area normal to the flow. For each cylinder several values of the drag coefficients were obtained in the range of Reynolds number, $R e=1.0 \times 10^{4}-1.0 \times 10^{5}$ and the average value of the drag coefficients for each aspect ratio is then compared in Fig. 1 with previous experimental results of Nakaguchi et al. [28], Bearman and 


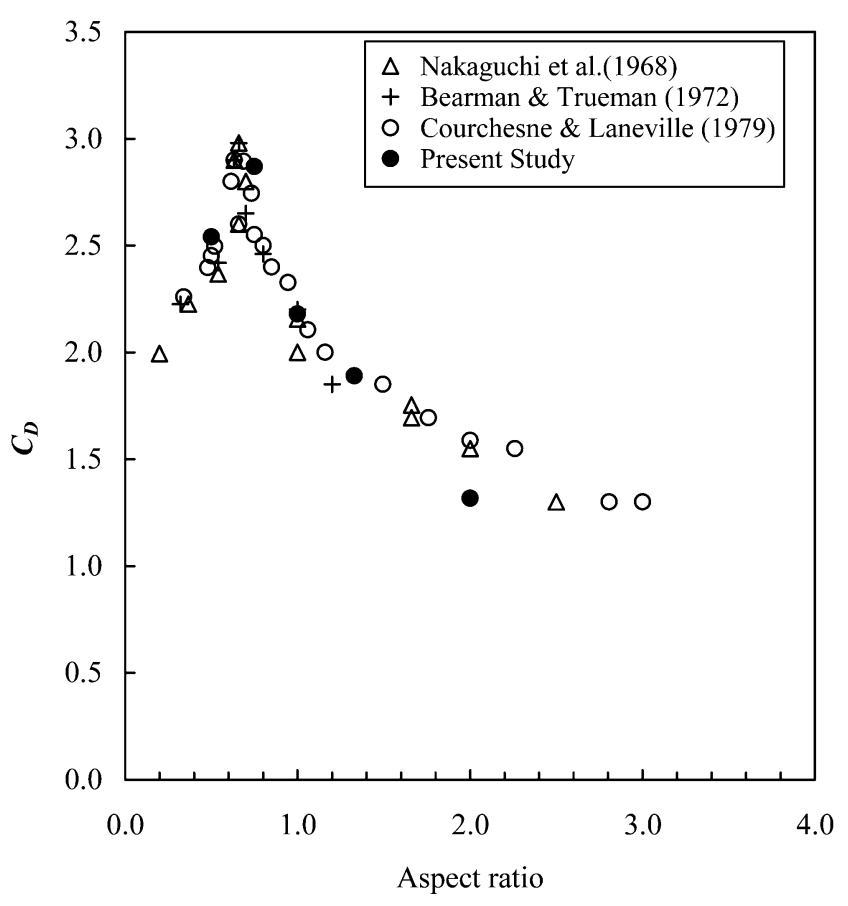

Fig. 1 Steady flow drag coefficients for rectangular cylinders
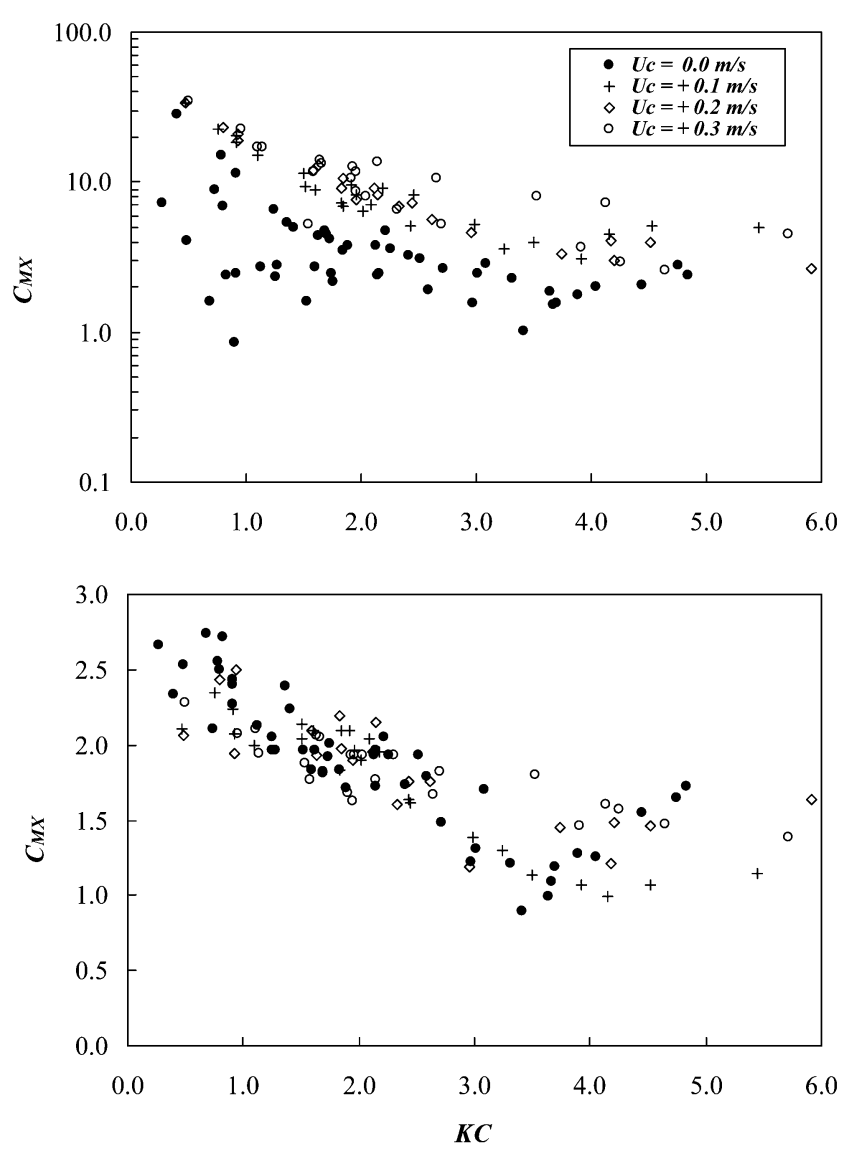

Fig. 2 Horizontal drag and inertia coefficients for square cylinder, aspect ratio $=1.0$ for positive currents
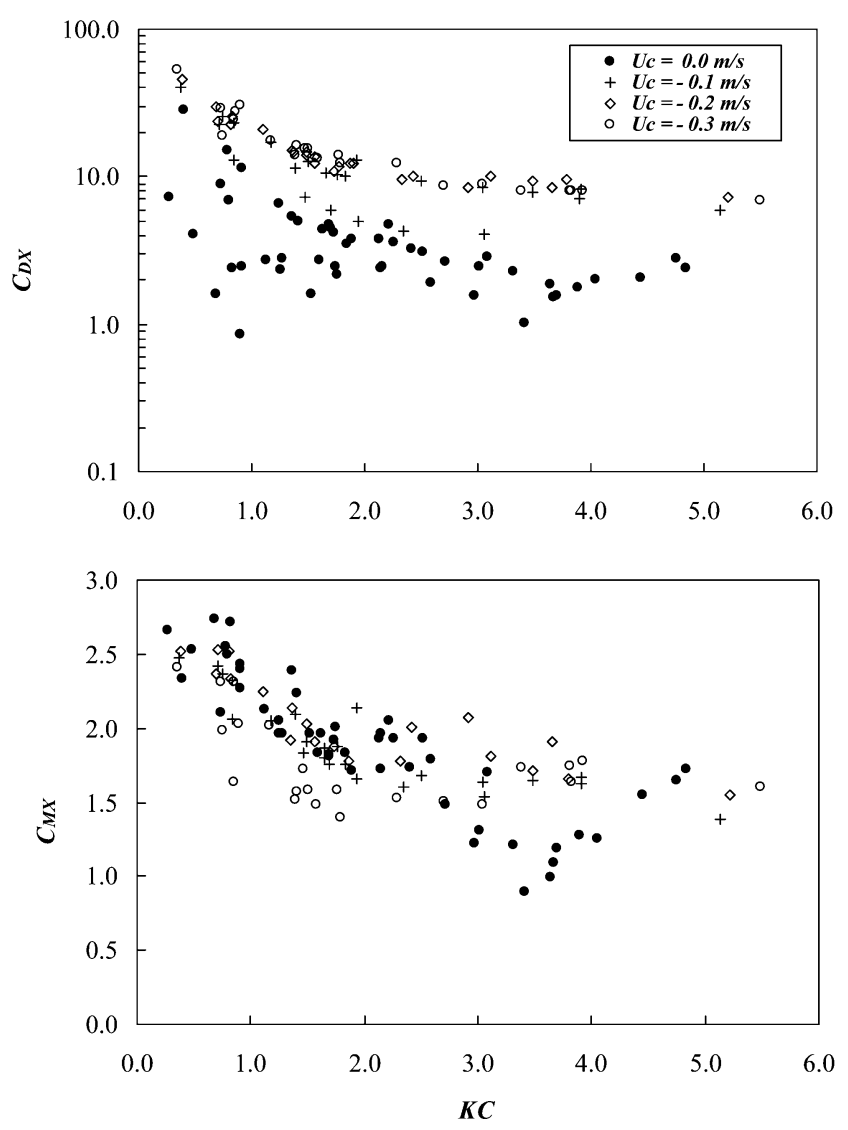

Fig. 3 Horizontal drag and inertia coefficients for square cylinder, aspect ratio $=1.0$ for negative currents

Trueman [29], and Courchesne and Laneville [30], who conducted experiments in wind tunnels. In general, the coefficients agree well, except for aspect ratio $=2$, for which a slightly lower drag coefficient was observed. These results indicate that the force measuring system works well for the range of Reynolds numbers tested.

\subsection{Cylinder with aspect ratio $=1.0$}

The force coefficients obtained for the horizontally submerged square cylinder in combined regular waves and currents are presented in Figs 2 to 5. Three current speeds were used, $U_{\mathrm{C}}= \pm 0.1 \mathrm{~m} / \mathrm{s}$, $\pm 0.2 \mathrm{~m} / \mathrm{s}$, and $\pm 0.3 \mathrm{~m} / \mathrm{s}$. The positive (following) current is one that is travelling in the same direction as the waves and negative (opposing) current is the one that is travelling opposite to the direction of the wave. The pure wave or no-current case is represented by $U_{\mathrm{C}}=0.0$.

In Figs 2 and 3, the variation of the drag and inertia coefficients in the horizontal $(x)$ direction for following (+ve) and opposing (-ve) currents is 

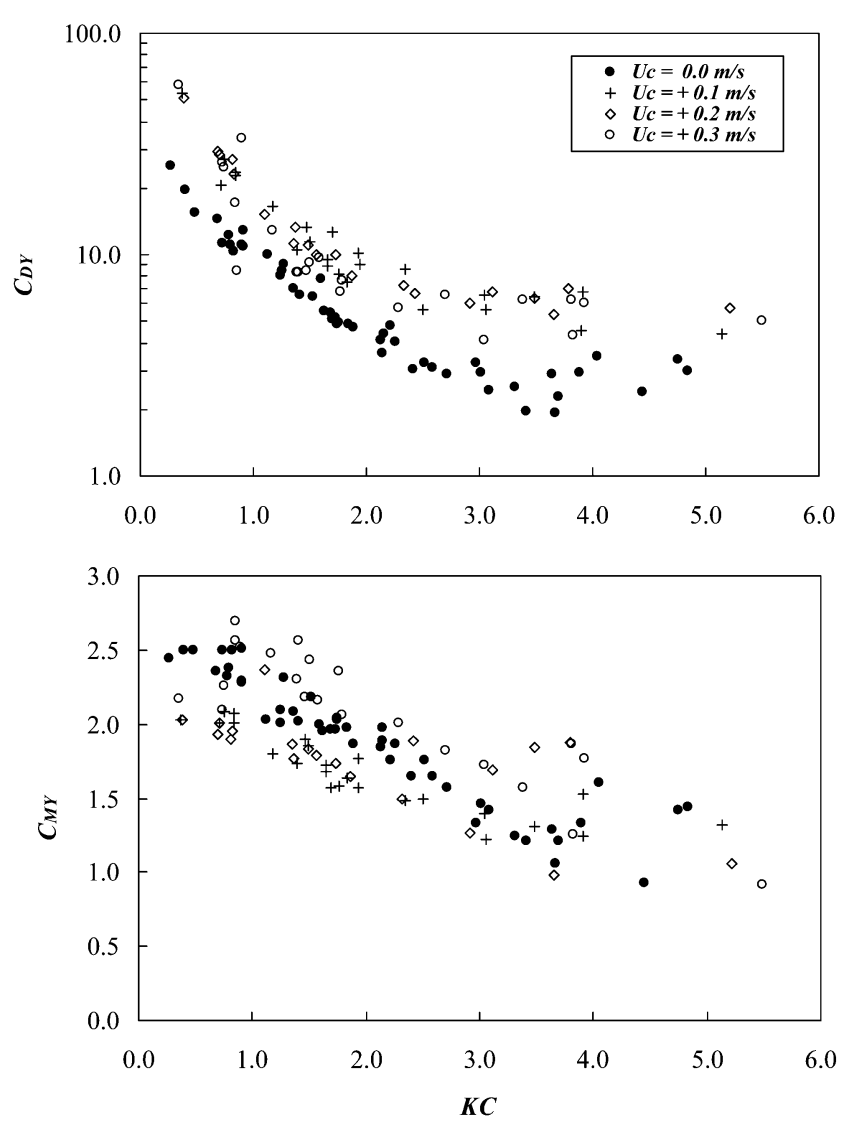

Fig. 4 Vertical drag and inertia coefficients for square cylinder, aspect ratio $=1.0$ for positive currents

shown. The drag and inertia coefficients obtained by Venugopal et al. [10] for waves alone or 'no-current' are also included in these plots for comparison. These plots reveal that the drag coefficients, $C_{\mathrm{D} X}$, in the horizontal direction, are significantly larger than the drag coefficients obtained for 'waves alone'. A similar trend is also seen in Figs 4 and 5 for vertical drag coefficients, $C_{\mathrm{DY}}$, for both the positive and negative currents. The inertia coefficients, $C_{\mathrm{MX}}$, (Figs 2 and 3) do not show any distinct difference between 'waves alone' and combined wave-current cases. On the other hand, many of the vertical inertia coefficients, $C_{\mathrm{MY}}$, in Figs 4 and 5 are found to be smaller than the 'waves alone' coefficients. The variation in current speed does not seem to influence the coefficients much as the values are found to be more or less the same.

In order to calculate theoretical wave forces, these coefficients are then used in the Morison equation (equations (3) and (4)) in conjunction with linear wave kinematics and wave forces are computed. Sample plots showing the comparison between measured and computed Morison forces are shown in Fig. 6 for the square and also for the rectangular
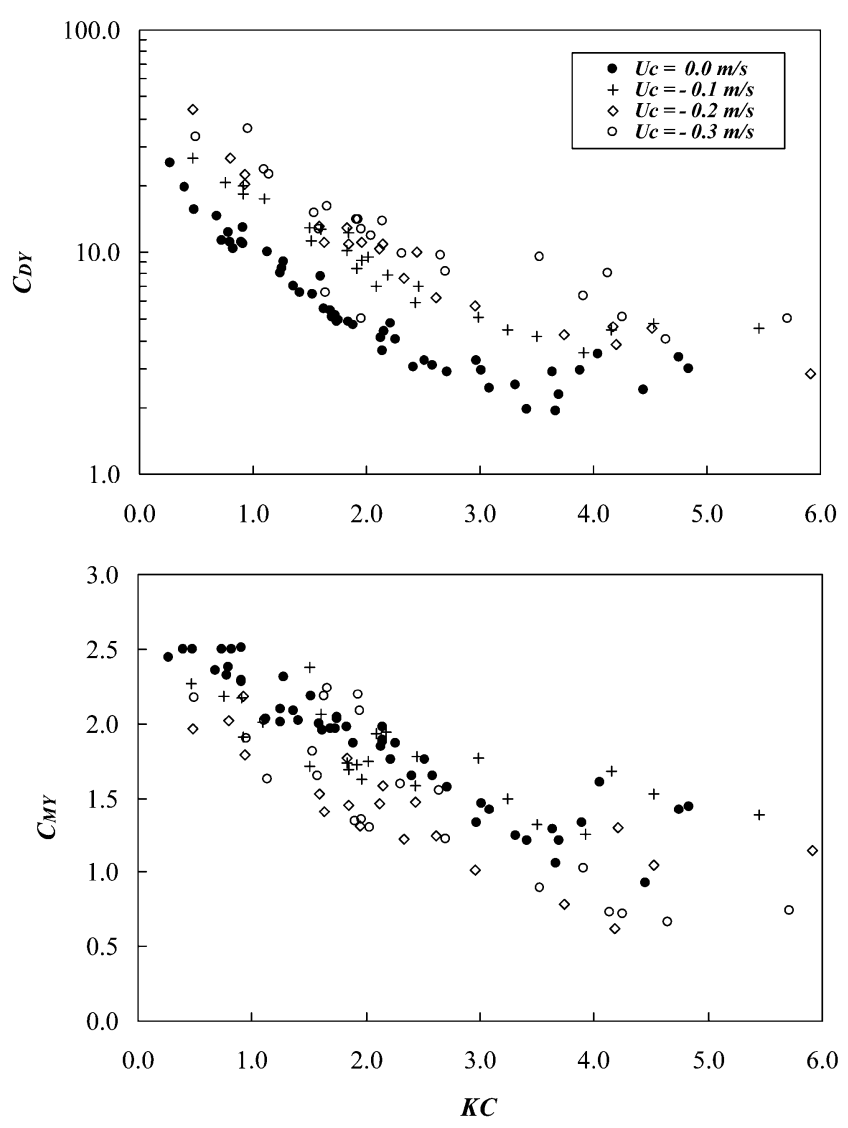

Fig. 5 Vertical drag and inertia coefficients for square cylinder, aspect ratio $=1.0$ for negative currents

cylinder with aspect ratio $=0.5$ (for which the force coefficients are given in section 5.3). It is evident from these plots that the measured forces show good agreement with the computed forces in both horizontal $(x)$ and vertical $(y)$ directions. However, some of the force records show significant differences at the peaks and troughs and therefore the measured peak force in each cycle is compared with the corresponding peak force computed by Morison equation. One such comparison for the square cylinder is shown in Fig. 7. Here each point represents the average over a complete time series. It is clear from this figure that the positive forces are underestimated and hence in order to compute an overall measure between computed and measured forces, the following ratio is defined

$$
R_{x p}=\frac{F_{x p}}{F_{x c}} ; \quad R_{y p}=\frac{F_{y p}}{F_{y c}}
$$

where $F_{x \mathrm{p}}, F_{y \mathrm{p}}$ are measured peak forces in $x$ and $y$ directions and $F_{x c}, F_{y c}$ are the computed peak forces using Morison equation in $x$ and $y$ directions using the respective drag and inertia coefficients. The peak forces are calculated from the average peaks over a 

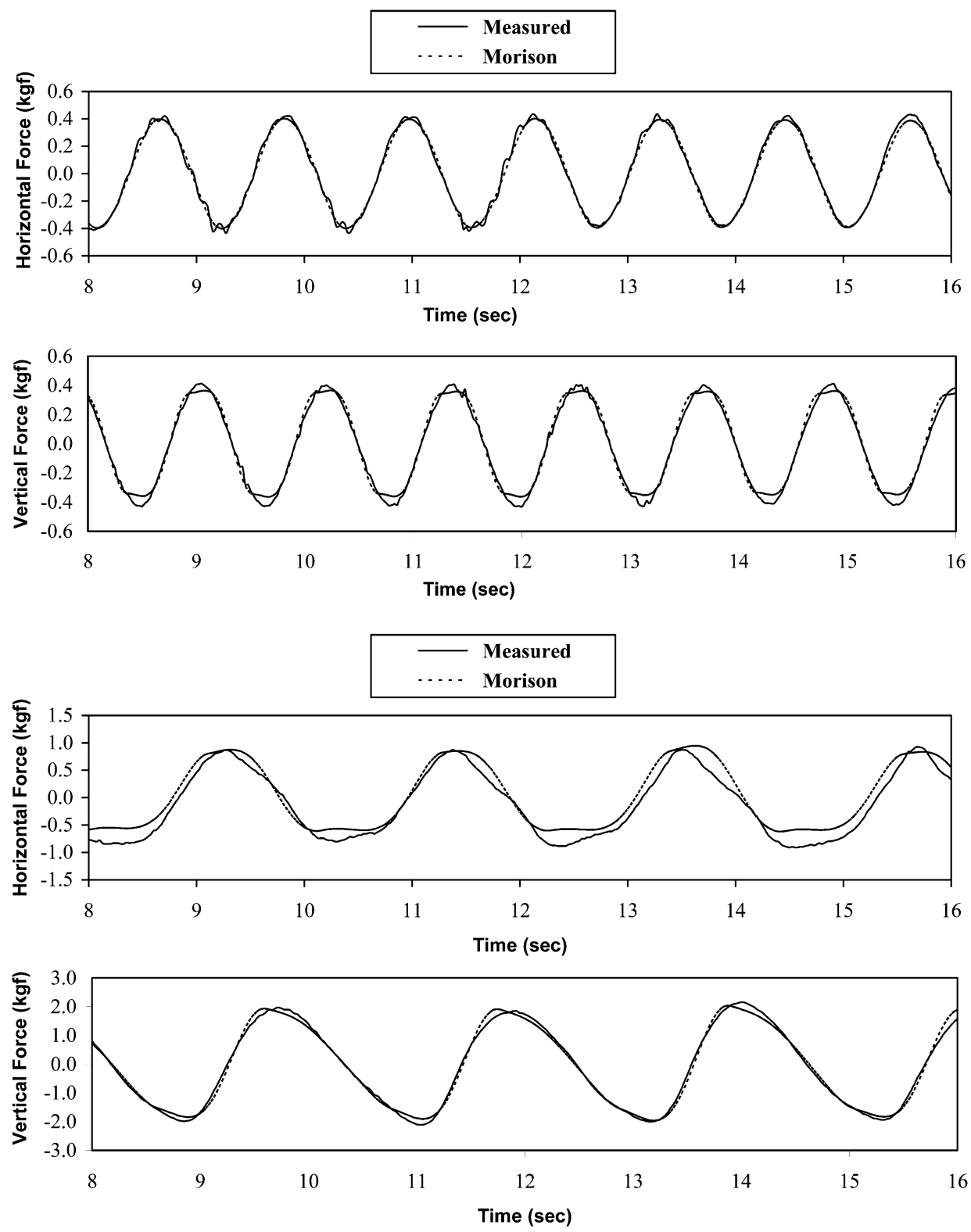

Fig. 6 Comparison between measured and computed forces: square cylinder for $K C=4.2$ (top) and rectangular cylinder with aspect ratio $=0.5$ for $K C=2.2$ (bottom)

complete time series. The mean $(\bar{R})$ and standard deviation $(\sigma)$ of this ratio for the square cylinder is as shown in Table 2. It can be seen from this table that for negative currents, $\bar{R}$ shows a large value for both horizontal and vertical forces, while the same ratio remains around 0.9-1.2 for positive currents. The maximum standard deviation is found to be about 30 per cent for horizontal force and about 25 per cent for the vertical force.

The above difference between measured and computed peak forces is noticed for all other rectangular cylinders tested (see Tables 3 and 4). The above error occurs in the range of $d / g T^{2}>0.14$ and $H / g T^{2}>0.0093$, where $d$ is the water depth, $H$ is the wave height, and $g$ is the gravitational constant. This error may be attributed to the use of linear wave theory for the particle kinematics computation. The range of $d / g T^{2}$ and $H / g T^{2}$, where the underprediction of peak forces occurs, indicates a region of higher order wave theories and, if the particle kinematics had been directly measured, this error could have been avoided.

\subsection{Cylinder with aspect ratio $=0.5$}

The variation of the drag and inertia coefficients for the rectangular cylinder with aspect ratio $=0.5$ is 

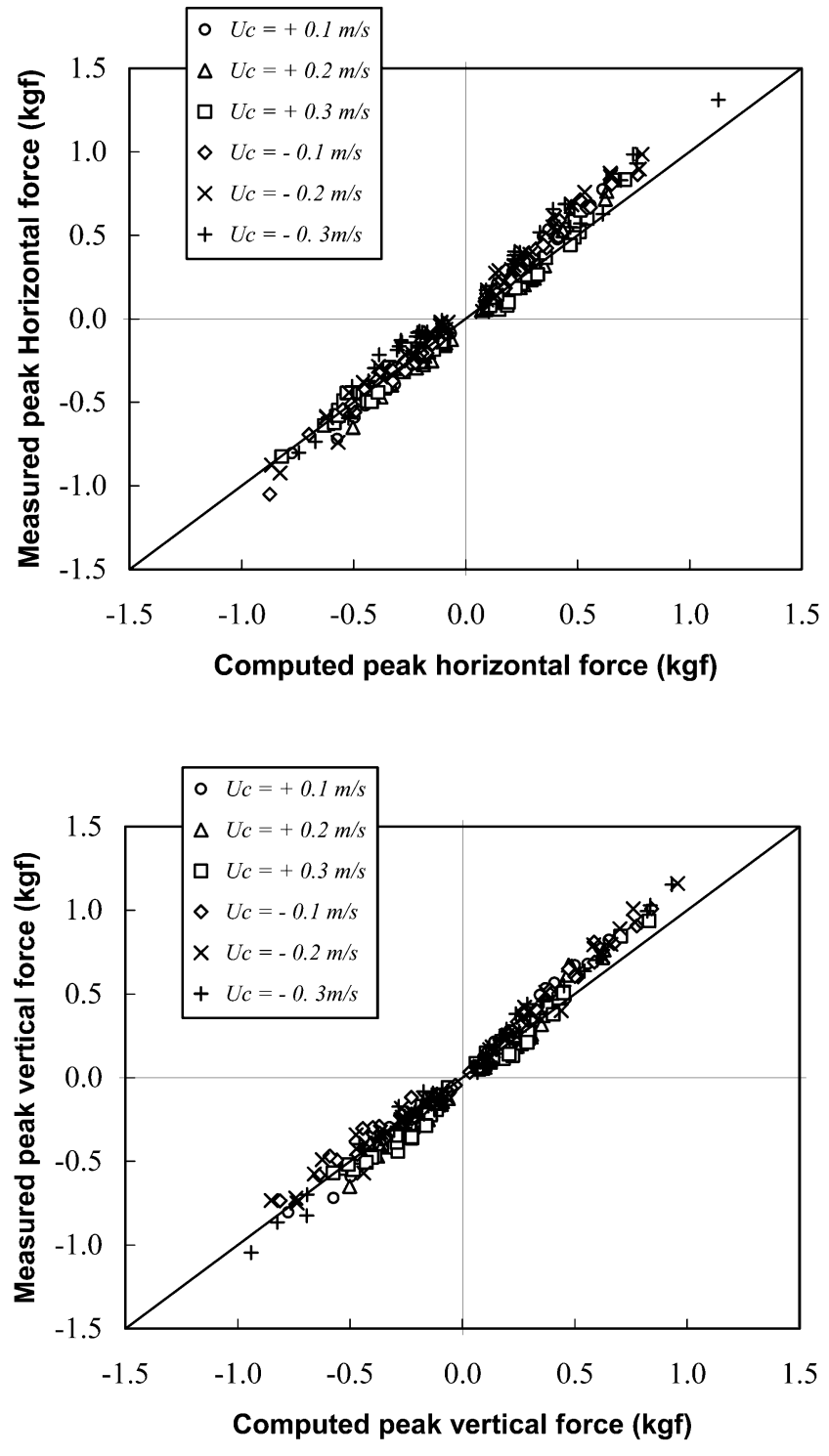

Fig. 7 Measured and computed peak forces for horizontal square cylinder

shown in Figs 8 to 11 . As in the case of the square cylinder, the horizontal drag coefficients $C_{\mathrm{D} X}$ are evidently much larger than the 'wave alone' drag

Table 2 Means and standard deviations of measured and computed peak force ratios for horizontal square cylinder in waves and currents

\begin{tabular}{lllll}
\hline & \multicolumn{4}{c}{ Aspect ratio $=1.0$} \\
\cline { 2 - 5 } Current $(\mathrm{m} / \mathrm{s})$ & $\bar{R}_{x \mathrm{p}}$ & $\sigma_{x \mathrm{p}}$ & $\bar{R}_{y \mathrm{p}}$ & $\sigma_{y \mathrm{p}}$ \\
\hline+0.1 & 1.268 & 0.137 & 1.152 & 0.186 \\
+0.2 & 0.942 & 0.246 & 0.947 & 0.209 \\
+0.3 & 0.938 & 0.283 & 0.966 & 0.225 \\
-0.1 & 1.270 & 0.107 & 1.172 & 0.190 \\
-0.2 & 1.397 & 0.284 & 1.214 & 0.176 \\
-0.3 & 1.379 & 0.294 & 1.225 & 0.256 \\
\hline
\end{tabular}

Table 3 Means and standard deviations of measured and computed peak force ratios for horizontal rectangular cylinder in waves and currents

\begin{tabular}{lllll}
\hline & \multicolumn{4}{c}{ Aspect ratio $=0.5$} \\
\cline { 2 - 5 } Current $(\mathrm{m} / \mathrm{s})$ & $\bar{R}_{x \mathrm{p}}$ & $\sigma_{x \mathrm{p}}$ & $\bar{R}_{y \mathrm{p}}$ & $\sigma_{y \mathrm{p}}$ \\
\hline+0.1 & 0.988 & 0.151 & 1.115 & 0.082 \\
+0.2 & 1.116 & 0.128 & 1.181 & 0.037 \\
+0.3 & 1.047 & 0.243 & 1.286 & 0.127 \\
-0.1 & 1.298 & 0.114 & 1.238 & 0.081 \\
-0.2 & 1.173 & 0.287 & 1.268 & 0.124 \\
-0.3 & 1.307 & 0.306 & 1.215 & 0.093 \\
\hline
\end{tabular}

Table 4 Means and standard deviations of measured and computed peak force ratios for horizontal rectangular cylinder in waves and currents

\begin{tabular}{lllll}
\hline & \multicolumn{5}{c}{ Aspect ratio $=0.75$} \\
\cline { 2 - 5 } Current $(\mathrm{m} / \mathrm{s})$ & $\bar{R}_{x \mathrm{p}}$ & $\sigma_{x \mathrm{p}}$ & $\bar{R}_{y \mathrm{p}}$ & $\sigma_{y \mathrm{p}}$ \\
\hline+0.1 & - & - & - & - \\
+0.2 & 1.304 & 0.107 & 1.286 & 0.059 \\
+0.3 & 1.415 & 0.141 & 1.216 & 0.097 \\
-0.1 & - & - & - & - \\
-0.2 & 1.503 & 0.117 & 1.261 & 0.119 \\
-0.3 & 1.663 & 0.169 & 1.202 & 0.110 \\
\hline
\end{tabular}
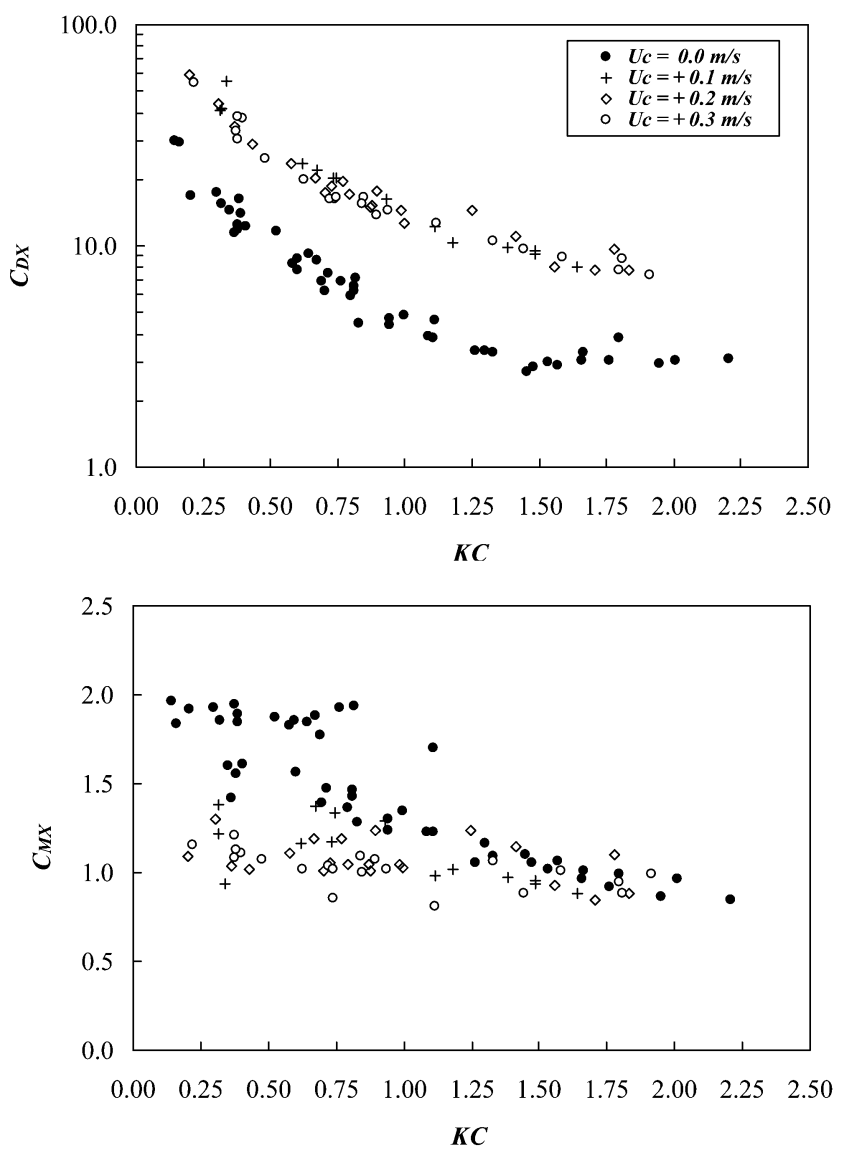

Fig. 8 Horizontal drag and inertia coefficients for rectangular cylinder, aspect ratio $=0.5$ for positive currents 

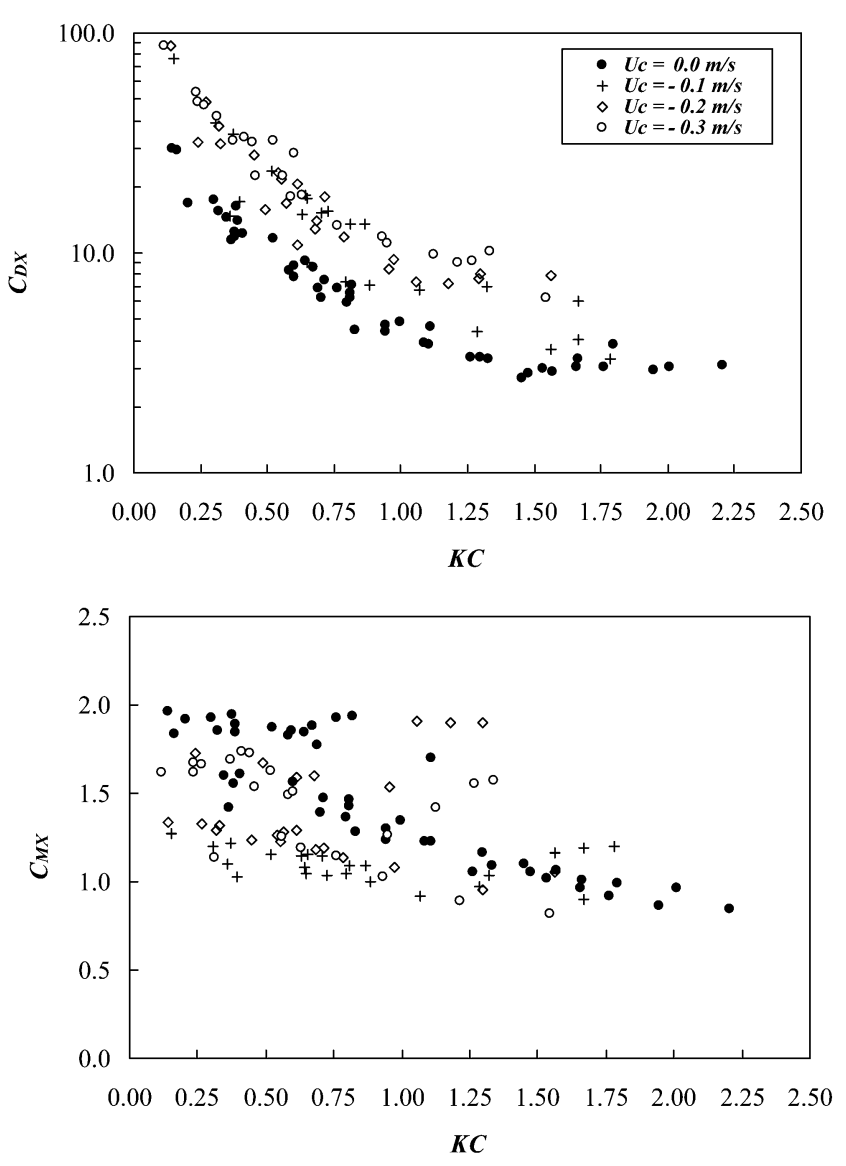

Fig. 9 Horizontal drag and inertia coefficients for rectangular cylinder, aspect ratio $=0.5$ for negative currents

coefficients. The $C_{\mathrm{D} X}$ for positive currents are about 3 to 3.5 times larger than the drag coefficients for waves alone and for negative currents the same is found to be 2 to 3 times larger than for waves alone. It is interesting to note that in the case of vertical forces (Figs 10 and 11), the drag coefficients in waves and currents are only slightly higher than the 'waves alone' coefficients for both positive and negative currents.

The inertia coefficients are distinctly smaller than the 'wave alone' inertia coefficients for both horizontal and vertical directions. Generally, the $C_{\mathrm{M} X}$ and $C_{\mathrm{M} Y}$ are found to be lower than the respective inertia coefficients obtained for waves alone for both positive and negative currents. However, some of the values of $C_{\mathrm{M} X}$ in Fig. 9 are observed to be larger than the 'wave alone' case. The mean and standard deviation of the measured and computed peak forces for all the current speeds are as given in Table 3. It can be seen from this table that for positive currents, both horizontal and vertical peak forces compare relatively well with Morison forces,
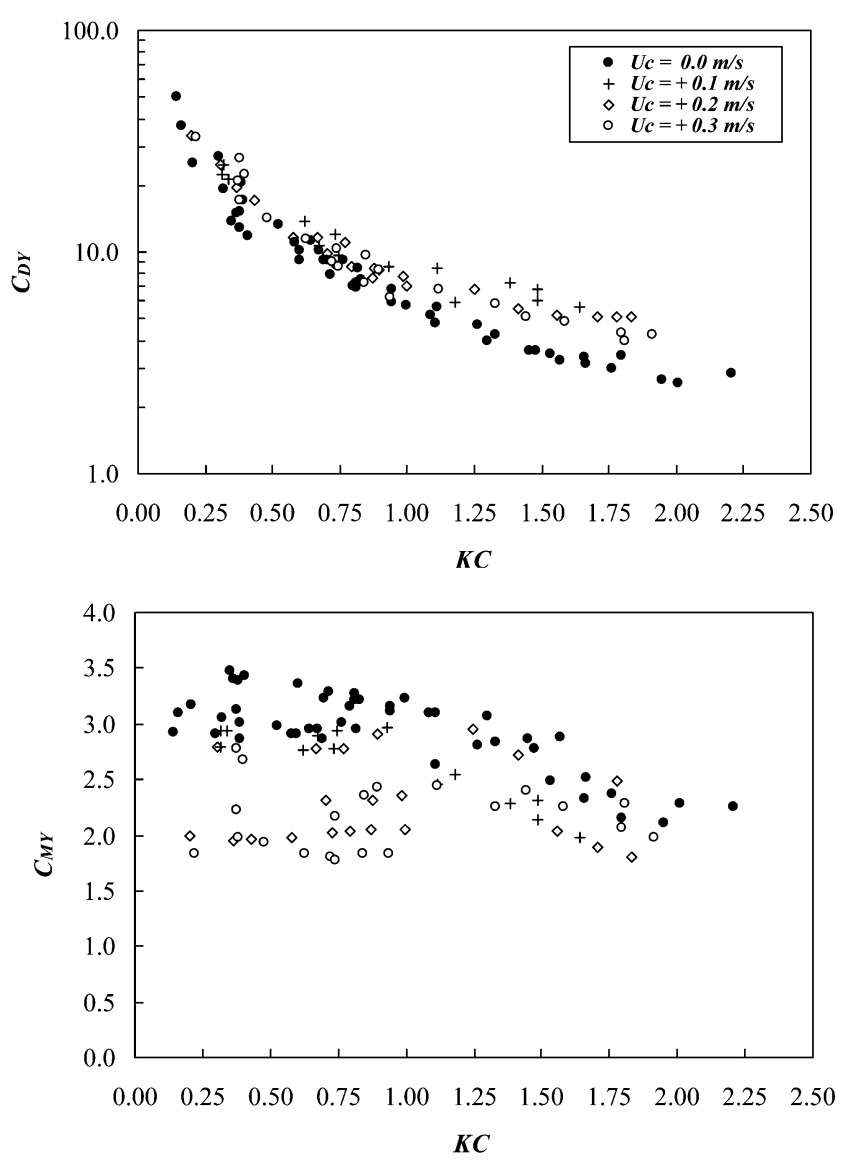

Fig. 10 Vertical drag and inertia coefficients for rectangular cylinder, aspect ratio $=0.5$ for positive currents

whereas in negative currents, a maximum mean difference up to about 30 per cent is obtained.

\subsection{Cylinder with aspect ratio $=0.75$}

The drag and inertia coefficients in the horizontal direction for aspect ratio $=0.75$ are shown in Figs 12 to 15 . For this aspect ratio, the results are available only for two current speeds, $U_{\mathrm{C}}= \pm 0.2$ and $\pm 0.3 \mathrm{~m} /$ $\mathrm{s}$. The values of the drag coefficients in Figs 12 to 13 do not show any considerable variation from the 'waves alone' drag coefficients for both positive and negative currents, with the exception of a few smaller $C_{\mathrm{D} X}$ values in Fig. 12 . The vertical drag coefficients in Figs 14 and 15 show a defined trend with 'wave alone' drag coefficients. However, for negative currents, $C_{\mathrm{D} Y}$ show slightly lower values in comparison with the 'waves alone' case (Fig. 15).

The $C_{\mathrm{MY}}$ values in Figs 14 and 15 for both positive and negative currents are found to be lower than 'waves alone' values and this trend is absent for $C_{\mathrm{M} X}$ in Fig. 12, where a large scatter is seen. The $C_{\mathrm{MX}}$ in 

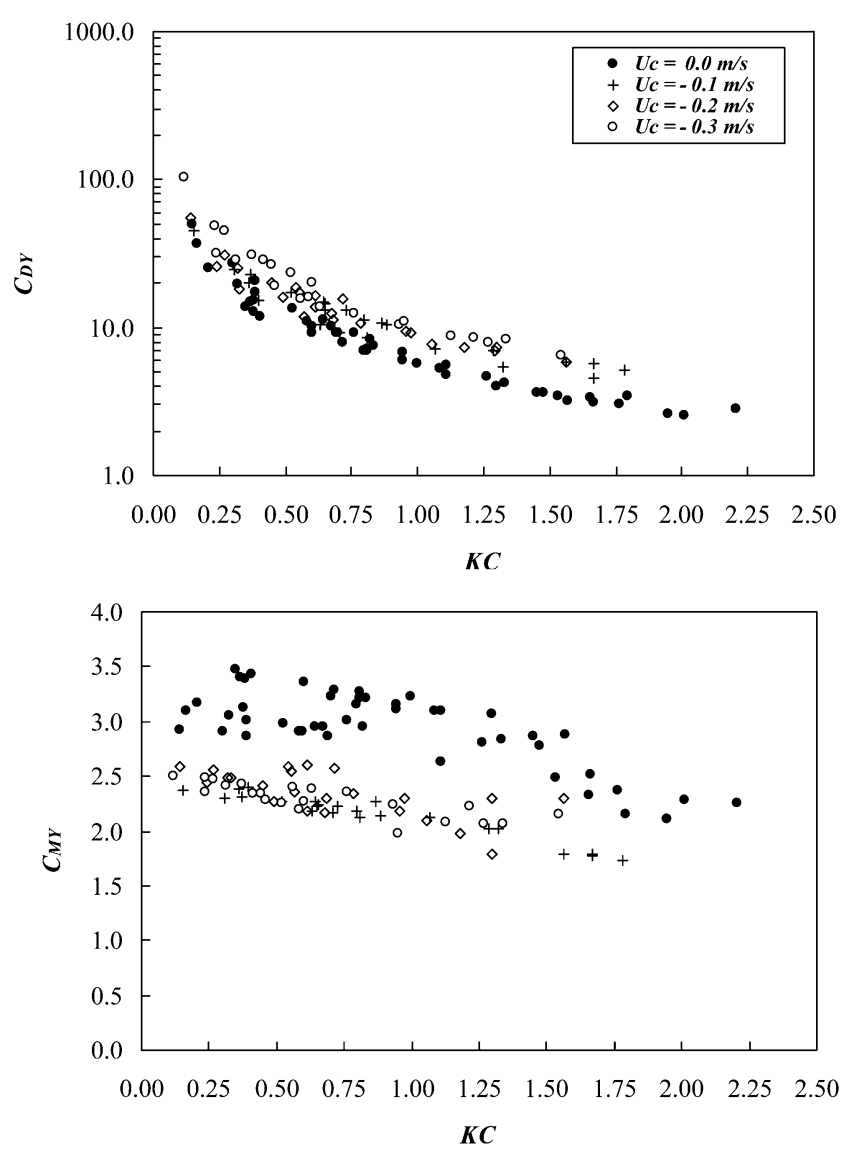

Fig. 11 Vertical drag and inertia coefficients for rectangular cylinder, aspect ratio $=0.5$ for negative currents

positive currents show values higher than the 'wave alone' coefficients at around $K C=1$, and the reason for this behaviour is unclear. The mean and standard deviation values are given in Table 4, where large differences between measured and computed forces are seen. The negative currents show a difference of up to 66 per cent between measured and Morison forces in the horizontal direction, whereas for the vertical direction, an average value of about 23 per cent is observed. The maximum standard deviations are around 16 per cent and 12 per cent in horizontal and vertical directions respectively.

For aspect ratios 0.5 and 0.75 , while most of the values of the inertia coefficients in waves and currents are less than or equal to 'no-current' values, some of the inertia coefficients are much higher than the 'no-current' force coefficients. Because it is difficult to investigate and describe the flow phenomenon around the cylinder without proper velocity field measurements, the authors believe that this could be due to the poor estimation of wave kinematics by the linear wave theory. Furthermore, for all three cylinders, inclusion of a current
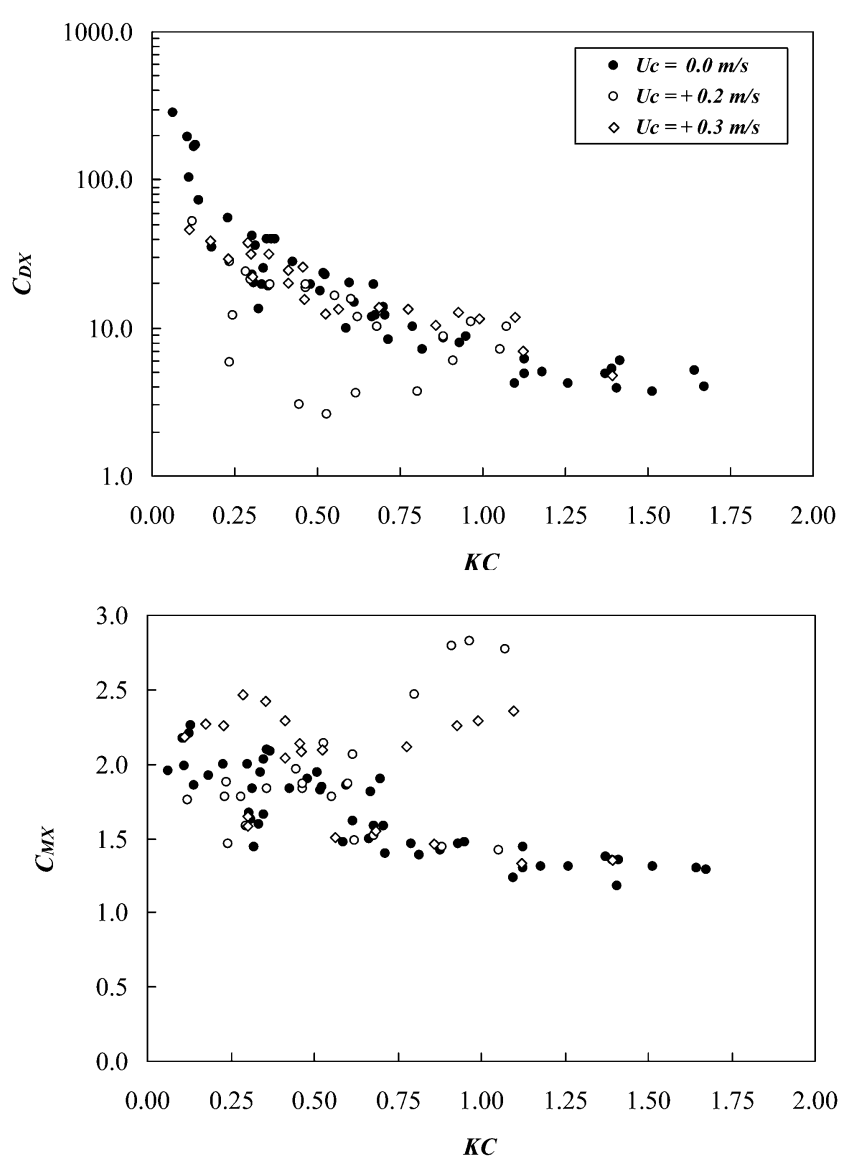

Fig. 12 Horizontal drag and inertia coefficients for rectangular cylinder, aspect ratio $=0.75$ for positive currents

produces force coefficients which are different from 'wave alone' values. In addition no appreciable difference has been observed between the force coefficients corresponding to different current speeds, and all three current velocities seem to produce almost similar values. However, it is difficult to say that any further increase in current speed would still produce the same magnitude of coefficients as obtained here and therefore the results should be used with caution.

According to Dean [31] if the inertia force components tend to dominate, reasonable resolution in the inertia coefficients can be expected and the data are better conditioned for determining inertia coefficients, along with contamination of the calculated drag coefficients. In the present results, the values of Dean's index, $R$, have been evaluated for all three horizontal cylinders. The maximum value of $R$ obtained is about 0.35 . This indicates that the data are well conditioned for determining the inertia coefficients and, to some extent, the drag coefficients. However, a majority of the data are within the limit $R<0.25$, therefore 

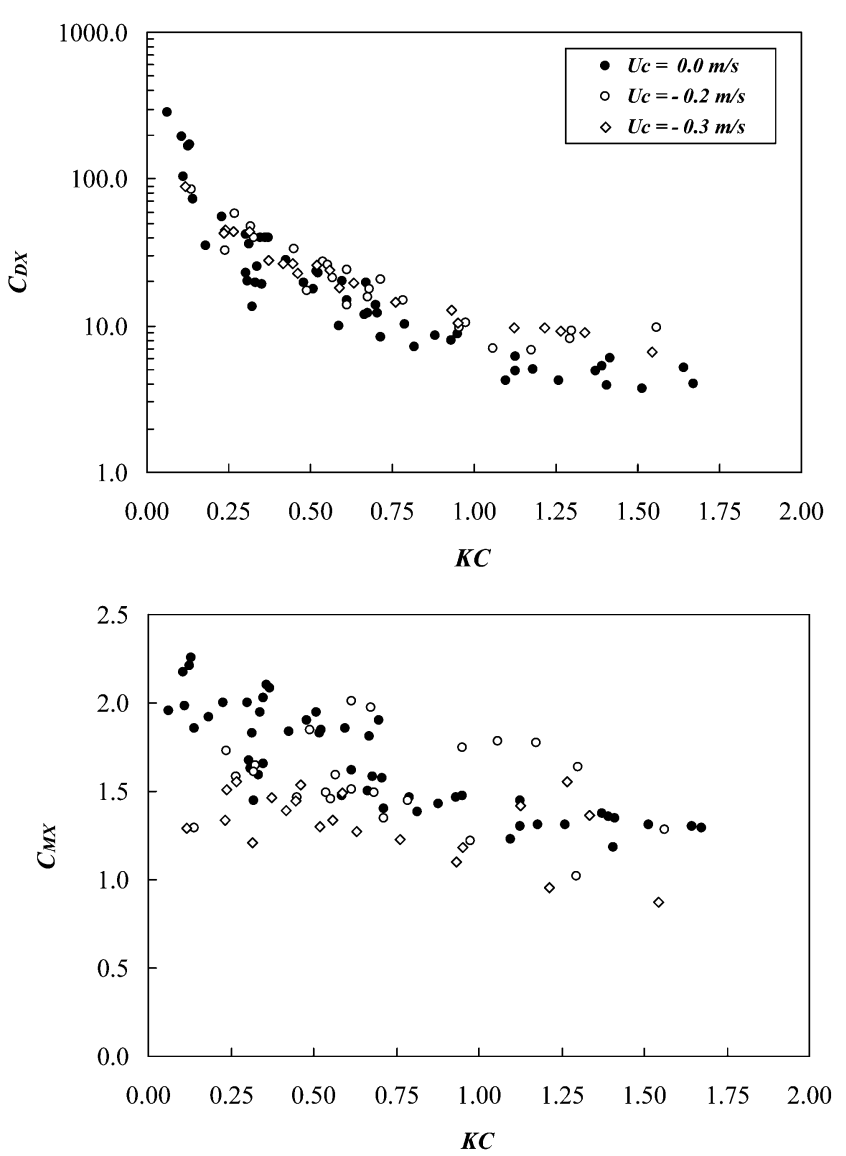

Fig. 13 Horizontal drag and inertia coefficients for rectangular cylinder, aspect ratio $=0.75$ for negative currents

suitability of the data for determining the drag coefficients is questionable. It has to be remembered that direct measurement of drag coefficients at very low $K C$ numbers is extremely difficult because the fluid loading is dominated by the inertia component. Bearman and Russell [32] gave a calculation that at $K C=1$ and $\beta=3 \times 10^{4}$, the maximum drag load in a cycle is only about 2 per cent of the maximum inertia load and at $K C=0.1$ it drops to about 1 per cent. Thus, at low $K C$ numbers the total force is mainly determined by inertial component and, since the conditioning of the data is more suitable for evaluating the inertia coefficients, the force calculation using the inertia coefficients as reported in this study can be safely carried out; even if it is thought that an error is involved in the drag coefficients.

\section{CONCLUSIONS}

The wave and current forces were measured on a section of a square section cylinder and two rectangular cylinders with aspect (breadth-depth)
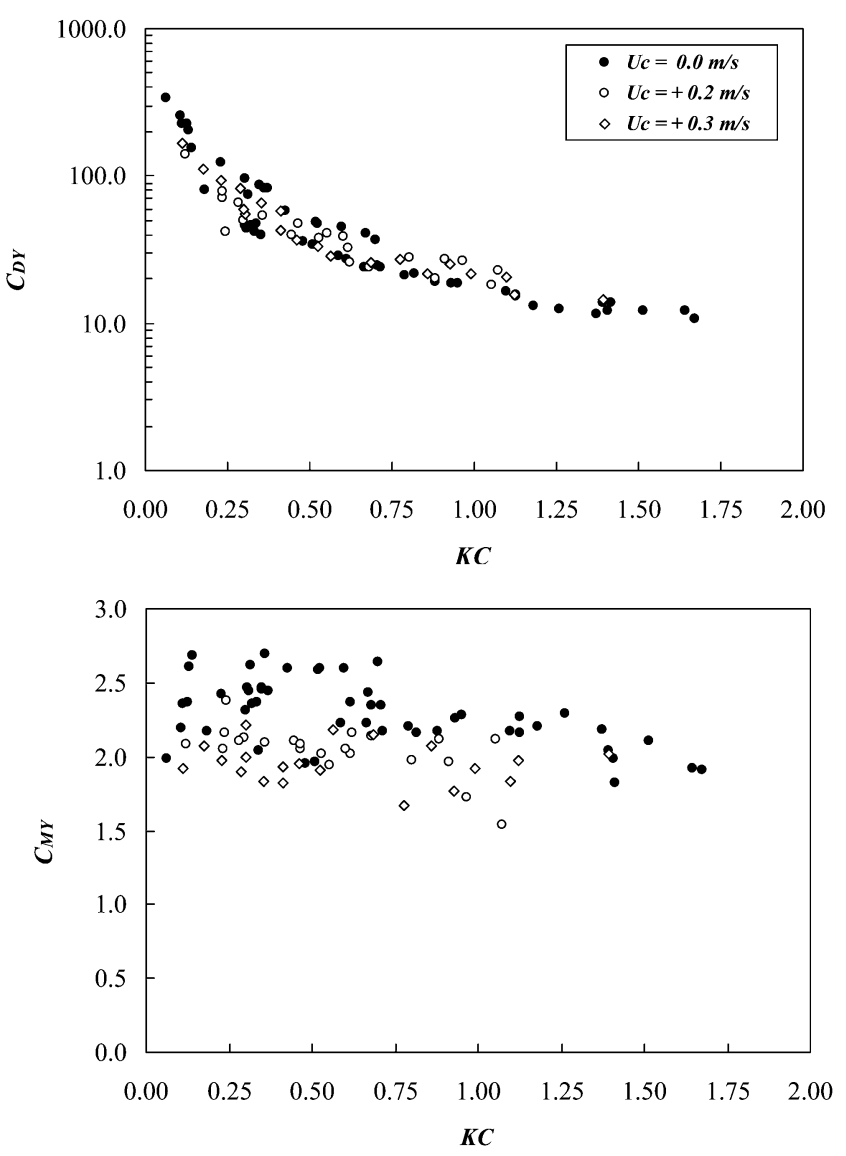

Fig. 14 Vertical drag and inertia coefficients for rectangular cylinder, aspect ratio $=0.75$ for positive currents

ratios equal to 0.5 and 0.75 . The cylinders were horizontally submerged in water with their axes parallel to the wave front. The measured sectional wave forces in the horizontal and vertical directions were used to calculate the drag and inertia coefficients for both directions using the Morison equation.

1. The analysis showed that for a square cylinder, in combined waves and currents, the horizontal and vertical component drag coefficients are generally larger than the 'waves alone' (or 'no-current') drag coefficients for both positive and negative currents. The inertia coefficient values are more or less the same as the 'waves alone' coefficients.

2. For a rectangular cylinder with aspect ratio $=0.5$, the drag coefficients in the horizontal direction are about 2 to 3.5 times larger than the waves alone' coefficients. The inertia coefficients for both horizontal and vertical directions are significantly lower than the 'waves alone' values.

3. For a rectangular cylinder with aspect ratio $=$ 0.75 , the presence of currents does not produce much variation in the drag coefficients in com- 

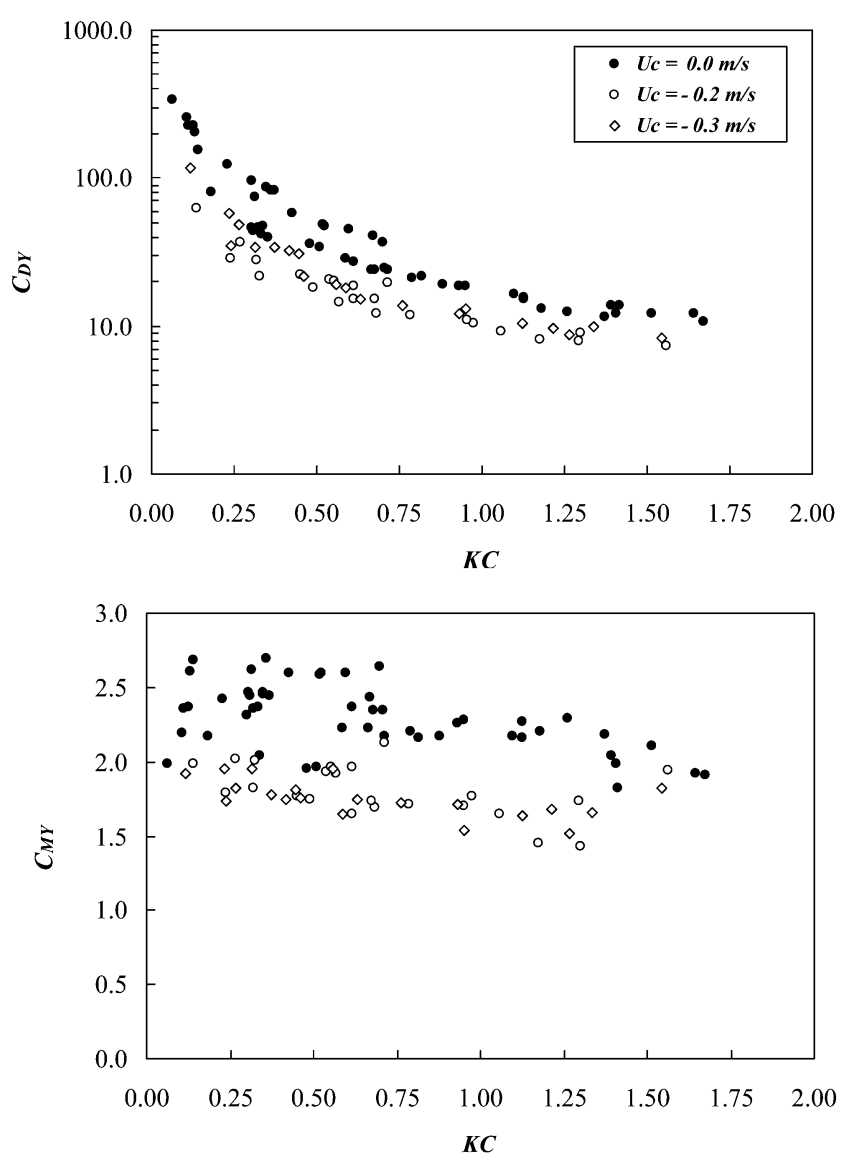

Fig. 15 Vertical drag and inertia coefficients for rectangular cylinder, aspect ratio $=0.75$ for negative currents

parison with the 'no-current' values. The vertical inertia coefficients are smaller than the "nocurrent' coefficients.

4. The underprediction of forces by Morison equation in combined waves and currents can be the result of a poor estimate of wave kinematics or may be attributable to a more complicated loading.

\section{ACKNOWLEDGEMENT}

The authors are members of The Engineering Committee on Oceanic Resources (ECOR), Oil \& Gas Panel, UK and would like to thank ECOR for their support.

\section{REFERENCES}

1 Bearman, P. W., Graham, J. M. R., and Singh, S. Forces on cylinders in harmonically oscillating flow. Proceedings of the Symposium on Mechanics of wave induced forces on cylinders, Bristol, 1979, pp. $437-449$.
2 Ikeda, Y., Otsuka, K., and Tanaka, N. Wave forces acting on horizontally submerged cylinders in regular waves at low $K C$ number. Report of Department of Naval Architecture, University of Osaka Prefecture, Japan, 1988, Report No. 00410.

3 Tanaka, N., Ikeda, Y., and Nishino, K. Hydrodynamic viscous force acting on oscillating cylinders with various shapes. Proceedings of 6th Symposium on Marine Technology, Society of Naval Architecture of Japan, 1982.

4 Ikeda, Y., Otsuka, K., and Tanaka, N. Viscous forces acting on a semi submersible. In Seventh International Conference on Offshore mechanics and arctic engineering, Houston, Texas, February 1988, pp. 101-108.

5 Chaplin, J. R. Nonlinear forces on a horizontal cylinder beneath waves. J. Fluid Mechanics, 1984, 147, 449-464.

6 Chaplin, J. R. Mass transport around a horizontal cylinder beneath waves. J. Fluid Mechanics, 1984, 140, 175-187.

7 Chaplin, J. R. and Retzler, C. H. Fluid loading on pontoon sections. Health and Safety Executive, 1992, OTI 91551.

8 Arai, S. Forces and circulation of horizontal cylinders submerged in regular waves. In Proceedings of the Third International Offshore and Polar Engineering Conference, Singapore, June 1993, Vol. 3, pp. 288-293.

9 Arai, S. Forces on and flows around a horizontal rectangular cylinder submerged in regular waves. In Proceedings of the Fifth International Offshore and Polar Engineering Conference, The Hague, The Netherlands, 1995, 6-11 June, Vol. 3, pp. 348-355.

10 Venugopal, V., Varyani, K. S., and Barltrop, N. D. P. Wave force coefficients for horizontally submerged rectangular cylinders. Ocean Engng, 2006, 33(11-12), 1669-1704.

11 Bearman, P. W., Graham, J. M. R., Obasaju, E. D., and Drossopoulos, G. M. Forces on cylinders in viscous oscillatory flow at low Kuelegan-Carpenter numbers. J. Fluid Mechanics, 1985, 154, 337-365.

12 Hamel-Derouich, D. Forces on vertical rectangular cylinders in wavy flow and in combined wave and current flow at low Keulegan-Carpenter numbers. In Proceedings of International Symposium on Offshore mechanics and arctic engineering, ASME, 1992, pp. 79-86.

13 Koterayama, W. and Hu, C. Wave forces on horizontal cylinders at low Keulegan-Carpenter and Reynolds numbers. In Proceedings of the 5th International Offshore and Polar Engineering Conference, The Hague, The Netherlands, 1995, pp. 189-195.

14 Chaplin, J. R. and Retzler, C. H. Influence of waves and current on separation and forces. OTH 93 409, Health and Safety Executive, 1993.

15 Bearman, P. W., Graham, J. M. R., Obasaju, E. D., and Drossopoulos, G. M. The influence of corner radius on the forces experienced by cylindrical 
bluff bodies in oscillatory flow. Appl. Ocean Res., 1984, 6, 83-89.

16 Chakrabarti, S. K. Nonlinear methods in offshore engineering, 1990 (Elsevier Science Publishers, New York).

17 Venugopal, V., Varyani, K. S., and Barltrop, N. D. P. An experimental investigation of hydrodynamic coefficients for a vertical truncated rectangular cylinder due to regular and random waves. Ocean Engng J., 2000, 27, 291-313.

18 Nakamura, M., Koterayama, W., and Hoshino, K. Three dimensional effects on hydrodynamic forces acting on an oscillating finite-length circular cylinder. Proceedings of the First International Offshore and Polar Engineering Conference, Edinburgh, UK, 11-16 August 1991, Vol. 3, pp. 143-148.

19 Hoshino, K., Kato, S., Saito, M., and Sato, H. Hydrodynamic forces acting on finite-length circular cylinder oscillating in a uniform flow. Proceedings of the Third International Offshore and Polar Engineering Conference, Singapore, 1993, Vol. 3, pp. 242-253.

20 Morison, J. R., O'Brien, M. P., Johnson, J. W., and Schaaf, S. A. The force exerted by surface waves on piles. Petrol. Trans., AIME, 1950, 189, 149-154.

21 Venugopal, V., Varyani, K. S., and Barltrop, N. D. P. Wave-current forces on rectangular cylinder at low KC numbers. Int. J. Offshore Polar Engng, 2000, 4, 276-284.

22 Pearcey, H. H. Some observations on fundamental features of wave-induced viscous flows past cylinder. Proceedings of Symposium on Mechanics of wave induced forces on cylinders, Bristol, 1979, pp. 1-54.

23 Chaplin, J. R. Loading on a cylinder in uniform oscillatory flow: Part II - elliptical orbital flow. Appl. Ocean Res., 1988, 104, 199-206.

24 Teng, C. C. and Nath, J. H. Forces on horizontal cylinder towed in waves. J. Waterway Port Coastal Ocean Engng Div., ASCE, 1985, 1116, 1022-1040.

25 Sarpkaya, T. and Storm, M. In-line force on a cylinder translating in oscillatory flow. Appl. Ocean Res., 1985, 75, 188-196.

26 Isaacson, M., Baldwin, J., and Niwinski, C. Estimation of drag and inertia coefficients from random wave data. J. Offshore Mech. Arctic Engng, 1991, 113, 128-136.

27 Det Norsk Veritas (DNV), Rules for planning and execution of marine operations, 1996, available from http://www.dnv.nl/energy/verification/warrantyservices.asp (accessed 20 February 2008).

28 Nakaguchi, H., Hashimoto, K., and Muto, S. An experimental study on aerodynamic drag of rectangular cylinders. J. Jap. Soc. Aero Space Sci., 1968, 16, $1-5$.

29 Bearman, P. W. and Trueman, D. M. An investigation of the flow around rectangular cylinders. The Aeronaut. Q., 1972, 23, 229-237.

30 Courchesne, J. and Laneville, A. A comparison of correction methods used in the evaluation of drag coefficient measurements of two-dimensional rec- tangular cylinders. Trans. ASME, J. Fluids Engng, 1979, 101, 506-510.

31 Dean, R. G.. Methodology for evaluating suitability of wave and wave force data for determining drag and inertia coefficients. Proceedings of the 1st International Conference on Behaviour of off-shore structures, BOSS'76, Trondheim, Norway, 1976, pp. 40-64.

32 Bearman, P. and Russell, M. Measurements of hydrodynamic damping of bluff bodies with applications to the prediction of viscous damping of TLP hulls. Twenty-first Symposium on Naval hydrodynamics, 1997, pp. 622-634 (National Academic Press, Trondheim, Norway).

\section{APPENDIX}

\section{Notation}

A

$B$

$C_{\mathrm{DX}}$

$C_{\mathrm{D} Y}$

$C_{\mathrm{MX}}$

$C_{\mathrm{M} Y}$

$D$

$d$

$F_{X}$

$F_{Y}$

$F_{x \mathrm{c}}$

$F_{y \mathrm{c}}$

$F_{x \mathrm{p}}$

$F_{y \mathrm{p}}$

$g$

H

$T$

$u$

$\dot{u}$

$U_{\mathrm{C}}$

$U_{\mathrm{m}}$

$w$

$\dot{w}$

$v$ cross-sectional area of the cylinder cylinder's section width in the horizontal direction drag coefficient in the horizontal direction drag coefficient in the vertical direction inertia coefficient in the horizontal direction inertia coefficient in the vertical direction cylinder's section depth in the vertical direction water depth wave force in the horizontal direction wave force in the vertical direction computed peak forces in the horizontal $(x)$ direction computed peak forces in the vertical (y) direction measured peak forces in the horizontal $(x)$ direction measured peak forces in the vertical (y) direction gravity constant wave height wave period horizontal particle velocity horizontal particle acceleration current velocity maximum horizontal particle velocity vertical particle velocity vertical particle acceleration

water density kinematic viscosity 